\title{
Health Indicators in Brazil
}

Aloyzio Cechella Achutti

Membro da Academia Sul-Rio-Grandense de Medicina e assessor do Instituto de Educação e Pesquisa do Hospital Moinhos de Vento - Porto Alegre, RS - Brazil

In the circulatory diseases chapter of this issue of Arquivos Brasileiros de Cardiologia, Dr. Gláucia M.M. Oliveira analyzes mortality data in the states of Rio de Janeiro, São Paulo, Rio Grande do Sul and their respective capitals, during the period of 1980-1999¹.

Fortunately, today it is possible to analyze currently available information on our population's ${ }^{2,3}$ health and diseases as in this article and transform it into indicators that allow us to better understand our reality and establish health policies. We are emerging from a period when the only data available about mortality was from other countries, and we tried to grossly extrapolate these statistics to our own population. We also went through a time when the distrust in our own [health] information served as an excuse to ignore it. Only by using and discussing information it is possible to improve its reliability.

At the 1977 Cardiology Congress in Porto Alegre, I presented, along with Dr. Sérgio Bassanesi, a brief communication on mortality due to cardiovascular diseases in Rio Grande do Sul ${ }^{4}$, consisting of a short series of gross data available with no elaborate statistical processing. At the time, poorly defined causes and cerebrovascular diseases were decreasing, whereas the rates of ischemic cardiopathy were increasing. We attributed this phenomenon to a redistribution of diagnoses, basically by the greater availability of cardiologists throughout the state's inland cities.

Two years later, in one of the sessions of the XXXV SBC Congress, Carlos Henrique Klein, one of the coauthors of this article, presented a study on mortality adjusted for cardiovascular diseases in Brazil weighted by age and poorly defined causes ${ }^{5}$. The theme was a leap forward, even though it was not duly appreciated at the time by the audience who was not prepared to recognize its importance.

When analyzing indicators, the discussion includes not only the phenomenon itself and the quality of data collection, but also the demographic, socioeconomic and political aspects of the statistics, challenging us to check for consistency with other available information, and with our own perceptions, prejudices and perspectives.
Although the indicators available today may not fully cover the entire Brazilian population due to its size, heterogeneity and ample distribution, they allow us to profile functionally defined populations of the capital cities. From all this information, however, figures related to mortality are the most widely available and traditionally used. Since 1970, our mortality statistics are accessible and need to be constantly reviewed and updated.

This article, therefore, along with others mentioned in the reference list, may be considered a favorable indicator of our capacity to study and understand the object of our daily clinical practice within a wider context with potential explanations for many yet unanswered questions, as well as a guide for our positions regarding health policies and our duties as citizens.

The authors show that in the three states and their capitals there is a steady trend of declining compensated and adjusted mortality rates, both for the circulatory diseases chapter as a whole, and its two primary specific components: ischemic heart disease and cerebrovascular diseases.

As discussed in the article, this is not a new finding, but it places us at the same level of other countries on the course of epidemiological progression. Although the tendency is the same, the degree of this drop varied from one population to another in the same period of time.

Since some determining factors (such as demographics and quality of information) for the differences observed among the populations studied were theoretically corrected, the challenge remains to seek additional explanations for this differential.

Certainly, doubts about the quality of the information [reliability of the statistics] may remain, especially considering the influence medical doctors are subject to when preparing death certificates. Another, more plausible explanation concerns the success of the public health system and life style changes, highly debatable in a relatively short period of time, and in which no transformations as significant are known regarding the potentiality of medical interventions and in behavior.

One cannot neglect characteristics more remote in space and time, such as the origin of each one of these populations (Rio and Rio Grande do Sul as expelling

Maling Address: Aloyzio C. Achutti - Av. Bastian, 212-90130-020-Porto Alegre, RS-Brazil E-mail: aloyzio.achutti@terra.com.br 
migrants and São Paulo as attracting migrants), as well as differences related to pregnancy and the initial vital cycle risks people were submitted to sixty or more years ago ${ }^{6}$.
The analysis, discussion and cross-matching of our health indicators, as well as the data discussed in the article, may reveal valuable information not yet recognized.

\section{REFERENCES}

1. Oliveira GMM, Souza e Silva NA, Klein CH. Mortalidade Compensada por Doenças Cardiovasculares no período de 1980 a 1999 - Brasil. Arq Bras Cardiol 2005; 85: 305-13.

2. DATASUS http://www.datasus.gov.br/ visitado em 7/06/2005.

3. Gadelha AMJ, IC, Valente JG, Schramm JMA, Portela MC, e Campos MR. Projeto carga de doença. Rio de Janeiro: ENSP/Fiocruz/ FENSPTEC, 2002.

4. Achutti A, Bassanesi S. Mortalidade por doenças cardiovasculares no Estado do Rio Grande do Sul - 10 anos. Tema livre no XXXIII
Congresso da Sociedade Brasileira de Cardiologia. Porto Alegre, 1977.

5. Klein $\mathrm{CH}$. A mortalidade por doenças cardiovasculares no Brasil no período de 1966-1975. Escola Nacional de Saúde Pública-Fiocruz. Tema apresentado em Congresso da Sociedade Brasileira de Cardiologia. Brasília, 1979.

6. Eriksson JG. The fetal origins hypothesis - 10 years on. Events before birth remain important, but we need to consider later modifiers too. BMJ 2005; 330: 1096. 